\title{
Random Forest Modeling for Fly Ash-Calcined Clay Geopolymer Composite Strength Detection
}

\author{
Priyanka Gupta ${ }^{1, *}$, Nakul Gupta $^{1}$, Kuldeep K. Saxena ${ }^{2}$ and Sudhir Goyal ${ }^{1}$ \\ 1 Department of Civil Engineering, Institute of Engineering \& Technology, GLA University, \\ Mathura 281406, India; naku1030588@gmail.com (N.G.); sudhir.goyal@gla.ac.in (S.G.) \\ 2 Department of Mechanical Engineering, Institute of Engineering \& Technology, GLA University, \\ Mathura 281406, India; saxena0081@gmail.com \\ * Correspondence: guptapriya2108@gmail.com
}

Citation: Gupta, P.; Gupta, N.; Saxena, K.K.; Goyal, S. Random Forest Modeling for Fly Ash-Calcined Clay Geopolymer Composite Strength Detection. J. Compos. Sci. 2021, 5, 271. https://

doi.org/10.3390/jcs5100271

Academic Editors: Swadesh

Kumar Singh, Suresh

Kumar Tummala,

Satyanarayana Kosaraju and Julfikar Haider

Received: 30 July 2021

Accepted: 7 September 2021

Published: 13 October 2021

Publisher's Note: MDPI stays neutral with regard to jurisdictional claims in published maps and institutional affiliations.

Copyright: (c) 2021 by the authors. Licensee MDPI, Basel, Switzerland. This article is an open access article distributed under the terms and conditions of the Creative Commons Attribution (CC BY) license (https:/ / creativecommons.org/licenses/by/ $4.0 /)$.

\begin{abstract}
Geopolymer is an eco-friendly material used in civil engineering works. For geopolymer concrete (GPC) preparation, waste fly ash (FA) and calcined clay (CC) together were used with percentage variation from 5,10 , and 15 . In the mix design for geopolymers, there is no systematic methodology developed. In this study, the random forest regression method was used to forecast compressive strength and split tensile strength. The input content involved were caustic soda with $12 \mathrm{M}, 14 \mathrm{M}$, and $16 \mathrm{M}$; sodium silicate; coarse aggregate passing $20 \mathrm{~mm}$ and $10 \mathrm{~mm}$ sieve; crushed stone dust; superplasticizer; curing temperature; curing time; added water; and retention time. The standard age of 28 days was used, and a total of 35 samples with a target-specified compressive strength of $30 \mathrm{MPa}$ were prepared. In all, $20 \%$ of total data were trained, and $80 \%$ of data testing was performed. Efficacy in terms of mean absolute error (MAE), root mean square error (RMSE), coefficient of determination $\left(\mathrm{R}^{2}\right)$, and MSE (mean squared error) is suggested in the model. The results demonstrated that the RFR model is likely to predict GPC compressive strength (MAE $=1.85 \mathrm{MPa}$, MSE $=0.05 \mathrm{MPa}, \mathrm{RMSE}=2.61 \mathrm{MPa}$, and $\left.\mathrm{R}^{2}=0.93\right)$ and split tensile strength $(\mathrm{MAE}=0.20 \mathrm{MPa}$, $\mathrm{MSE}=6.83 \mathrm{MPa}, \mathrm{RMSE}=0.24 \mathrm{MPa}$, and $\mathrm{R}^{2}=0.90$ ) during training.
\end{abstract}

Keywords: fly ash; calcined clay; compressive strength; tensile strength; random forest regressor

\section{Introduction}

Fly ash (FA) is a byproduct of the thermal power plant electricity-generation process [1]. It is carried by the burner gases and collected by using an electrostatic or mechanical separation [2]. Davidovits, a French scientist, first proposed geopolymers. Geopolymer technology is one of the potential alternatives for increasing the use of fly ash. Regarding global warming, the alkaline-enabled geopolymer technology using fly ash not only has the potential to substantially lower the carbon footprint of normal Portland cement concrete but also has an enormous scope as a supplementary binder for applications in composite manufacturing [3]. Efficient waste management is important to maintain a safe environment [4]. The mechanical properties of geopolymer concrete are dependent upon various factors, including initial temperature required in curing temperature, curing time in hours, the age of samples in days, percent of total volume aggregate, sodium hydroxide molarity (M) solution, $\mathrm{SiO}_{2}$ solid \% in sodium silicate, and superplasticizer (percent P) $[5,6]$. Because of the porosity in the geopolymer network, the compressive strength is poor. Fly ash, however, needs little $\mathrm{H}_{2} \mathrm{O}$ and pushes maximal fill-up of particles to lower porous content due to its round portion shape [7]. Calcined clay and fly ash were mixed and analyzed by roles of the addition, reactiveness, strength due to compression, structural and microstructural characteristics, and $\mathrm{CC}$ versus FA ratio. $\mathrm{Na}_{2} \mathrm{SiO}_{3} / \mathrm{NaOH}$ was synthesized as an activator with $0,25,50$, and $75 \%$ fly ash and calcined clay percentage in geopolymer mortar [8]. From the academic research, 357 data points were obtained, and the compressive strength of high strength concrete was predicted by using an ensemble random forest (RF) and gene 
expression programming (GEP) algorithm. A proportioned blend trial mix requires us to determine a specific response. However, engineers are now using mathematical models to simulate a specific response to verify the prediction's performance, such as linear regression, neural networks (NN), or support vector regression (SVR). Since the relationship between attributes and composite properties is strongly nonlinear, everything is achieved [9]. The dataset provides data on cement ratio, silicate ratio, pulverized time, age of the specimen, and strength due to compression. With an increasing number of trees in random forest regression (RFR), the inaccuracy in predicting data beyond the test dataset decreases, and after 600 tries, the inaccuracy would become steady and very reduced. With an $R^{2}$ value of 0.89 , the random forest model forecasted strength due to compression, using input datasets obtained by laboratory experiments [10]. Cement/fly-ash-based high-performance composite has 56 datasets. RFR was used to detect 28 days' strength due to compression. The RFR model and the back-propagation neural network (NN) model used a common dataset to predict strength selection of functions with and without [11]. Ground granulated blast furnace slag was gathered with 453 experimental samples, using the RFR model, to calculate the strength due to compression of concrete, including GGBFS [12]. Rubberized concrete (RC) is a cost-effective and eco-sustainable building material. There are a total of 138 datasets collected from the literature. The present study suggested establishing the connection between both the random forest $(\mathrm{RF})$ and beetle antennae algorithm to search the essential factors of random forest. The result analysis showed the beetle antennae algorithm adjusted by RF. The correlation coefficient is strong in this case, as the proposed random forest model can accurately predict rubberized concrete's compressive strength with a correlation coefficient of 0.96 [13]. Table 1 offers a brief description of previously performed random forest regression studies. Fly-ash-and-calcined-clay-based geopolymer composites have much less research.

Table 1. List of RFR-related literature reviews.

\begin{tabular}{|c|c|c|}
\hline Reference & Model & Output Description \\
\hline$[7]$ & RFR & Compressive strength of cement \\
\hline$[8]$ & $\begin{array}{c}\text { RFR and Backpropagation } \\
\text { neural network }\end{array}$ & $\begin{array}{l}\text { Strength due to compression of } \\
\text { cement/fly-ash-based } \\
\text { high-performance composite }\end{array}$ \\
\hline$[9]$ & RFR and GEP & $\begin{array}{c}\text { Compressive strength of high } \\
\text { strength composite }\end{array}$ \\
\hline$[10]$ & RFR & $\begin{array}{l}\text { Strength due to compression of } \\
\text { GGBFS composite. }\end{array}$ \\
\hline$[11]$ & RFR & $\begin{array}{c}\text { Strength due to compression of GGBFS } \\
\text { rubberized geopolymer composite } \\
\text { compressive strength }\end{array}$ \\
\hline
\end{tabular}

In the current study, 35 samples were gathered from experimental work. As FA and CC are available as waste materials, they were mixed at varying proportions of $5 \%, 10 \%$, and $15 \%$, along with different ingredients, such as coarse aggregate (passing $10 \mathrm{~mm}$ and $20 \mathrm{~mm}$ IS sieve), stone dust as fine aggregate, $\mathrm{NaOH}(12 \mathrm{M}, 14 \mathrm{M}$, and $16 \mathrm{M}), \mathrm{Na}_{2} \mathrm{SiO}_{3}$, superplasticizer, and added water; and different curing temperatures were used, such as ambient, $80^{\circ} \mathrm{C}$, and $100^{\circ} \mathrm{C}$, with different curing durations, such as 24 and $48 \mathrm{~h}$. The actual compressive strength obtained was predicted by using random forest regression. A total of $80 \%$ of samples were tested, and $20 \%$ of samples were trained by using RFR. The R square value describes the acceptability of a model. This machine learning approach saves the cost and time of tedious laboratory work.

\section{Materials and Methods}

\subsection{Fly Ash}

Fly ash following IS 3812-2003 specification was collected from Suratgarh thermal power plant, Rajasthan. The particle density of the fly ash was $2250 \mathrm{~kg} / \mathrm{m}^{3}$. The chemical 
composition of fly ash and \% of the mass are mentioned in Table 2. The 5\%,10\%, and $15 \%$ of fly ash were substituted with calcined clay. The physical properties of fly ash were fineness retained on the 45-micron sieve; activity index test results lie between 80 and $86 \%$, with a specification of minimum $75 \%$ at 28 days and $95-103 \%$ specification of minimum $85 \%$ at 90 days. The particle size distribution of fly ash has a significant impact on geopolymer concrete [14]. Raising the curing temperature has a beneficial compressionstrength influence. Because of the porosity in the geopolymer network, the compressive strength declines.

Table 2. Chemical composition of fly ash and \% of mass.

\begin{tabular}{cc}
\hline Component & Composition \\
\hline Silica & $50-52.5$ \\
Alumina & $28.5-30.5$ \\
Ferric oxide & $2-3$ \\
Calcium oxide & $6-9.5$ \\
Magnesium oxide & $2-2.5$ \\
Potassium oxide & $<1$ \\
Na equivalent & $<1.5$ \\
Titanium dioxide & $1.5-2.0$ \\
\hline
\end{tabular}

\subsection{Calcined Clay}

The calcined clay was prepared generally by burning the clay at $550{ }^{\circ} \mathrm{C}$ for one hour. The mechanical activation was accomplished by milling the clay for $4 \mathrm{~h}$ in a ring mill. This was bought from a place named Alwar in Rajasthan, India. It is obtained by calcining clay at a higher temperature. Clay is available as a natural source in abundance in many places. Calcined clay was used with $5 \%, 10 \%$, and $15 \%$ variations of fly ash in geopolymer concrete. The calcined clay was used in geopolymer mortar preparation in one study, but no study was found using it in geopolymer concrete [14].

\subsection{Sodium Silicate Solution}

$\mathrm{Na}_{2} \mathrm{SiO}_{3}$ is called water glass, and it is also accessible as a gel. The ratio of $\mathrm{SiO}_{2}$ to $\mathrm{Na}_{2} \mathrm{O}$ in this study was 1.95 to 2.3. It was obtained from the market in liquid solution form. The chemical composition of it was $\mathrm{Na}_{2} \mathrm{O} 13.5 \%, \mathrm{SiO}_{2} 33 \%$, and water. The chemical composition can be seen in Table 3 .

Table 3. Percentage mass composition of chemical compounds of sodium silicate activator.

\begin{tabular}{cccc}
\hline Component & $\mathbf{S i O}_{2}$ & Water & $\mathbf{N a}_{2} \mathbf{O}$ \\
\hline Composition & 33 & 53.5 & 13.5 \\
\hline
\end{tabular}

\subsection{Sodium Hydroxide}

Sodium hydroxide was purchased from the local market from Bhiwadi (Rajasthan) in solid-chip form. It was mixed with drinking water to obtain $12 \mathrm{M}, 14 \mathrm{M}$, and $16 \mathrm{M}$ of $\mathrm{NaOH}$ solution. By blending calcined clay and fly ash with the alkaline agent, the geopolymers pastes were prepared. The activator's alkalinity was adjusted by mixing it with different molarity sodium hydroxide.

\subsection{Superplasticizer}

Polycarboxylate ether was used as a superplasticizer. Its amount was kept as $1 \%$ of the total amount of fly ash. 


\subsection{Aggregate}

\subsubsection{Fine Aggregate/Crushed Stone Dust}

There is a ban on sand, and its availability is very costly, so sand was replaced by stone crusher dust. Stone dust was available in abundance in nearby places in Rajasthan, and it was abundantly used in concrete. Thus, the same stone crusher dust was used in geopolymer concrete. This is following IS 383 specifications. Table 4 shows the physical properties of stone dust.

Table 4. Physical characteristics of the stone dust.

\begin{tabular}{ccccc}
\hline Serial No. & Property & Natural Sand & Stone Dust & IS Codes \\
\hline 1 & Specific Gravity & 2.6 & $2.53-2.68$ & IS2386(Part III)-1963 \\
2 & Bulk Density & 1460 & $1710-1850$ & IS2386(Part III)-1963 \\
3 & Absorption & nil & $1.2-1.5$ & IS2386(Part III)-1963 \\
4 & Moisture & 1.5 & nil & IS2386(Part III)-1963 \\
5 & Content & Zone II & Zone II & IS 383-1970 \\
\hline
\end{tabular}

\subsubsection{Coarse Aggregate}

Locally available aggregate varying from 10 to $20 \mathrm{~mm}$ in size was used as aggregate.

\subsection{Sample Preparation and Testing Method}

First, $12 \mathrm{M}, 14 \mathrm{M}$, and $16 \mathrm{M}$ of $\mathrm{NaOH}$ solution were prepared one day before use by dissolving solid caustic soda in water. The prepared sodium oxide solution was then mixed with sodium silicate solution to prepare an alkaline activator. The alkaline activator ratio was kept at 2.5. To obtain a uniform mix, all the dry ingredients, such as fly ash, calcined clay, stone dust, and aggregate, were mixed for $3 \mathrm{~min}$, as mentioned in Table 5, before adding an alkaline activator. Later, the alkaline activator and superplasticizer and required amount of water were added to the dry mixture and rotated in the concrete mixture for two minutes. After preparing the geopolymer concrete mixture, it was poured into a $100 \mathrm{~mm}$ cube mold to test the compressive strength and tensile strength. All concrete-filled specimens were kept for drying at room temperature for a day. Then the samples were removed from the mold and kept for curing at different temperatures. The geopolymer concrete was prepared with a $5-15 \%$ variation of fly ash with calcined clay. The prepared samples were then cured at ambient temperature, $80^{\circ} \mathrm{C}$, and $100{ }^{\circ} \mathrm{C}$ for 24 and $48 \mathrm{~h}$. Thus, heat-cured samples were removed from the oven after 24 and $48 \mathrm{~h}$ and kept at room temperature. Then 28-day compressive strength and the 28-day tensile strength were found. The slump of above-prepared concrete was also found.

Table 5. Description of mix proportions for different FA-CC-based geopolymer concrete.

\begin{tabular}{|c|c|c|c|c|c|c|c|}
\hline Samples & FA (\%) & CC (\%) & $\begin{array}{c}\mathrm{NaOH} \\
\text { (M) }\end{array}$ & $\begin{array}{l}\text { Temperature } \\
\text { Curing }\left({ }^{\circ} \mathrm{C}\right)\end{array}$ & $\begin{array}{l}\text { Duration of } \\
\text { Curing } \\
\text { (h) }\end{array}$ & $\begin{array}{l}\text { Aging Time } \\
\text { (days) }\end{array}$ & $\begin{array}{l}\text { Added } \\
\text { Water }\end{array}$ \\
\hline 5C1FA & 95 & 5 & 12 & 30 & 24 & 28 & 56.92 \\
\hline $5 \mathrm{C} 2 \mathrm{FA}$ & 95 & 5 & 12 & 80 & 24 & 28 & 56.92 \\
\hline 5C3FA & 95 & 5 & 12 & 80 & 48 & 28 & 56.92 \\
\hline 5C4FA & 5 & 5 & 12 & 100 & 24 & 28 & 56.92 \\
\hline 5C5FA & 95 & 5 & 12 & 100 & 48 & 28 & 56.92 \\
\hline 5C6FA & 95 & 5 & 14 & 30 & 24 & 28 & 39.5 \\
\hline 5C7FA & 95 & 5 & 14 & 80 & 24 & 28 & 39.5 \\
\hline 5C8FA & 95 & 5 & 14 & 80 & 48 & 28 & 39.5 \\
\hline 5C9FA & 95 & 5 & 14 & 100 & 24 & 28 & 39.5 \\
\hline 5C10FA & 95 & 5 & 14 & 100 & 48 & 28 & 39.5 \\
\hline 5C11FA & 95 & 5 & 16 & 30 & 24 & 28 & 47.36 \\
\hline $5 \mathrm{C} 12 \mathrm{FA}$ & 95 & 5 & 16 & 80 & 24 & 28 & 47.36 \\
\hline
\end{tabular}


Table 5. Cont.

\begin{tabular}{|c|c|c|c|c|c|c|c|}
\hline Samples & FA $(\%)$ & CC (\%) & $\begin{array}{c}\mathrm{NaOH} \\
\text { (M) }\end{array}$ & $\begin{array}{l}\text { Temperature } \\
\text { Curing }\left({ }^{\circ} \mathrm{C}\right)\end{array}$ & $\begin{array}{l}\text { Duration of } \\
\text { Curing } \\
\text { (h) }\end{array}$ & $\begin{array}{l}\text { Aging Time } \\
\text { (days) }\end{array}$ & $\begin{array}{l}\text { Added } \\
\text { Water }\end{array}$ \\
\hline 5C13FA & 95 & 5 & 16 & 80 & 48 & 28 & 47.36 \\
\hline 5C14FA & 95 & 5 & 16 & 100 & 24 & 28 & 47.36 \\
\hline 5C15FA & 95 & 5 & 16 & 100 & 48 & 28 & 47.36 \\
\hline 10C1FA & 90 & 10 & 12 & 30 & 24 & 28 & 59.2 \\
\hline $10 \mathrm{C} 2 \mathrm{FA}$ & 90 & 10 & 12 & 80 & 24 & 28 & 59.2 \\
\hline 10C3FA & 90 & 10 & 12 & 80 & 48 & 28 & 59.2 \\
\hline 10C4FA & 90 & 10 & 12 & 100 & 24 & 28 & 59.2 \\
\hline $10 \mathrm{C} 5 \mathrm{FA}$ & 90 & 10 & 12 & 100 & 48 & 28 & 59.2 \\
\hline 10C6FA & 90 & 10 & 14 & 30 & 24 & 28 & 49.3 \\
\hline 10C7FA & 90 & 10 & 14 & 80 & 24 & 28 & 49.3 \\
\hline $10 \mathrm{C} 8 \mathrm{FA}$ & 90 & 10 & 14 & 80 & 48 & 28 & 49.3 \\
\hline 10C9FA & 90 & 10 & 14 & 100 & 24 & 28 & 49.3 \\
\hline 10C10FA & 90 & 10 & 14 & 100 & 48 & 28 & 49.3 \\
\hline 15C1FA & 85 & 15 & 14 & 30 & 24 & 28 & 45.3 \\
\hline 15C2FA & 85 & 15 & 14 & 80 & 24 & 28 & 45.3 \\
\hline 15C3FA & 85 & 15 & 14 & 80 & 48 & 28 & 45.3 \\
\hline 15C4FA & 85 & 15 & 14 & 100 & 24 & 28 & 45.3 \\
\hline 15C5FA & 85 & 15 & 14 & 100 & 48 & 28 & 45.3 \\
\hline 15C6FA & 85 & 15 & 16 & 30 & 24 & 28 & 51.3 \\
\hline 15C7FA & 85 & 15 & 16 & 80 & 24 & 28 & 51.3 \\
\hline $15 \mathrm{C} 8 \mathrm{FA}$ & 85 & 15 & 16 & 80 & 48 & 28 & 51.3 \\
\hline 15C9FA & 85 & 15 & 16 & 100 & 24 & 28 & 51.3 \\
\hline 15C10FA & 85 & 15 & 16 & 100 & 48 & 28 & 51.3 \\
\hline
\end{tabular}

Abbreviations: FA, fly ash; $\mathrm{CC}$, calcined clay; $\mathrm{NaOH}$, sodium hydroxide.

\section{Modeling Technique}

A prediction of the compression strength and tensile strength of the fly ash-calcined clay geopolymer composites was performed with random forest regression in the current study. The following are briefly described.

\subsection{Random Forest Research (RFR)}

Ho [15] was the first to develop the general method of random decision forest in 1995. Leo Breiman [16] created an extension of the algorithm. The term "random forest" refers to a collection of decision tree algorithms. As a classifier, the random forest algorithm consists of two phases, one is a selection of the feature, and the other is classification. Random forest (RF) is a group classifications used to increase precision. There are many decisionmaking trees in the random forest. In comparison to traditional classification algorithms, random forests have low ranking errors. Minimum size and number of trees, nodes, and characteristics are used to split each node [17]. Random forest is a non-parametric method derived from classification and regression trees. RF includes a mixture of several trees, where each bootstrap sample is generated for every tree, having left around onethird of the total validation sample. A random subset of the determinants at every node is used to determine each split of the tree. The result is that all trees have averaged results [18]. Random forest is a machine learning approach governed by a group that has just evolved [19]. The toughness of an independent decision tree and the relationships between base trees are important elements in determining the random forest classifier's generalization error [16]. In this way, research has been conducted to attempt to restrain the decision trees and discover the best subset of the random forest. Random forest trimming will result in a productive random forest regression for training, as well as testing. Because of bootstrap samples and, in particular, randomized classification techniques at every level of the tree, the random forest produces good results [20]. 


\subsection{Projected Approach/Proposed Strategy}

Figure 1 depicts the methodological approach for our suggested method.

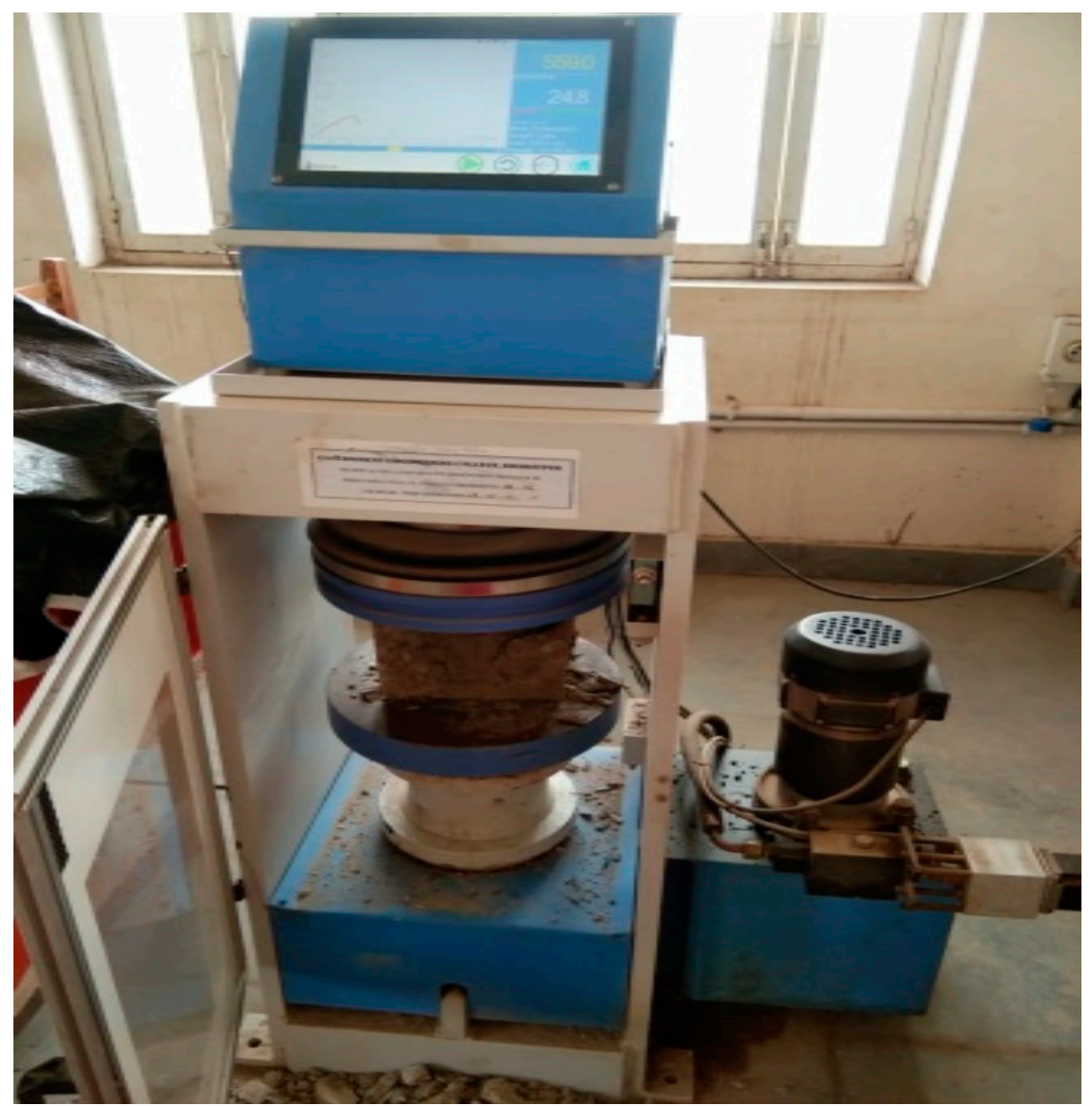

Figure 1. Experimental setup of fly-ash/calcined-clay-based geopolymer concrete.

\section{Data Collection}

Experimental data on calcined clay and fly ash were collected from laboratory work. A total of 35 datasets were prepared from an experimental approach. Out of 35 datasets, 28 were trained on the random forest model, and the testing of 7 datasets was conducted. Figure 2 well explain the procedure of collected data modeling. The following Algorithm 1 is our proposed work.

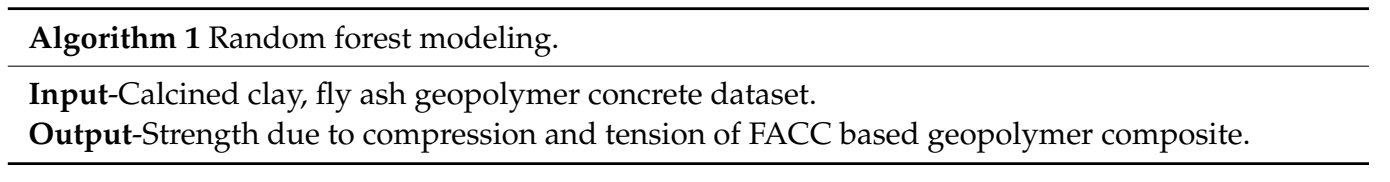

Stage-by-stage procedure of RFR modeling:

Stage 1: Data loading.

Stage 2: Use a preprocessing method.

Stage 3: Divide the dataset into training and test categories.

Stage 4: Random forest is used to train on the dataset.

Stage 5: For classification, the test dataset is supplied into a random forest.

Stage 6: Calculate the accuracy, errors, and precision. 


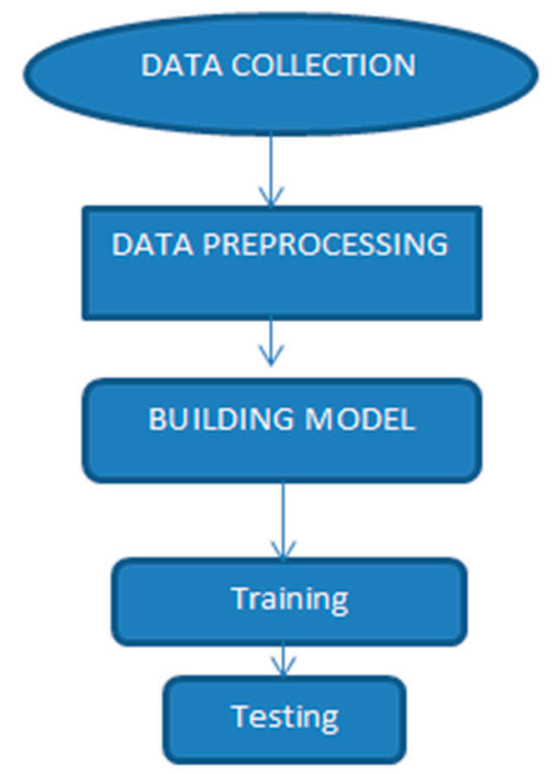

Figure 2. Proposed approach sequence of actions.

\subsection{Analysis of Model Performance}

Different metrics were used to demonstrate the feasibility of each prototype and to analyze the performance. Every other indicator has the formula of deducting the model's performance. The commonly used metrics include root mean square error (RMSE), mean absolute error (MAE), mean squared error (MSE), and $R^{2}$. These factors are described below in mathematical terms.

$$
\begin{gathered}
\text { MAE }=\frac{1}{n} \sum_{i=1}^{n}\left|x_{i}-x\right| \\
\text { MSE }=\frac{1}{n} \sum_{i=1}^{n}\left(y_{\text {pred }}-y_{\text {ref }}\right)^{2} \\
\text { RMSE }=\sqrt{\sum \frac{\left(y_{\text {pred }}-y_{\text {ref }}\right)^{2}}{n}} \\
\mathrm{R}^{2}=1-\frac{\mathrm{Y}_{n}-\mathrm{Y}_{\text {pred }}}{\mathrm{Y}_{n}-\mathrm{Y}_{\text {mean }}}
\end{gathered}
$$

where $n$ was the total number of datasets, $x$ and $y_{\text {ref }}$ were reference values in the dataset, and $x_{i}$ and $y_{\text {pred }}$ were predicted values of models. The performance of the model was also assessed in this paper by using the coefficient of determination $\left(\mathrm{R}^{2}\right)$. The reflective practice that reveals the connection between experimental and expected outputs was the value obtained through the model [21].

\section{Results and Discussion}

The prediction efficiency of the developed random forest regressor models was assessed in by utilizing training and testing datasets. The training set was utilized to evaluate the design and model parameters. The test dataset, on the other hand, was used only if the succeeding regressor had been defined to assess the model's quality.

(1) Tables 6-9 illustrate the results of the various statistical metrics of the models for both the training and testing phases, based on the projected values for compressive strength and split tensile strength.

(2) In the case of compressive strength RFR, the $R^{2}$ was determined to be 0.93 in the training dataset. Similarly, the $\mathrm{R}^{2}$ was obtained as 0.58 in the testing phase. Furthermore, 
RFR was shown to have the best value among the statistical measures used in testing as $(\mathrm{MSE}=10.41, \mathrm{RMSE}=3.22, \mathrm{MAE}=3.07)$. The RFR model excels at capturing the nonlinear interactions between geopolymer mix design proportions and temperatures with compressive strength, which could explain its supremacy. Consequently, since it relies on empirical analytical evaluations, it may be inferred that the RFR model produced the desired results [8,22].

(3) The $\mathrm{R}^{2}$, MAE, and RMSE of the predicted values, using the RFR, were also calculated [23]. For split tensile strength the training dataset, MSE, RMSE, ${ }^{2}$, and MAE values were $0.88,0.25,0.88$, and 0.0256 , respectively. Using the RFR technique, calculate the $\mathrm{R}^{2}, \mathrm{MAE}$, and RMSE of the anticipated values [24]. This research could help engineers choose optimal supervised learning models and parameters for geopolymer concrete manufacturing. This graph suggests that employing the RFR model could be beneficial. To forecast the strength due to compression of geopolymer concrete at various temperatures, 12 input variables are sufficient and have reasonable precision. Using a set of 12 input variables could be justified and useful for practical and engineering applications, according to the findings. $\mathrm{R}^{2}$ is regarded as very weak, low, medium, or strong if ranges as $>0.3,0.3<\mathrm{r}<0.5,0.5<\mathrm{r}<0.7$, or $\mathrm{r}>0.7$, respectively [25].

(4) The highest $R^{2}$ score and the fewest other errors have shown some positive results with appropriate dimensions [26]. Figure 3, has an $\mathrm{R}^{2}$ score of 0.93 , which show that model is highly trained.The mean MSE for RFR is 6.35 and 5.803 for training and testing data. The predictive precision and widespread potential of the RFR are high [11]. There is a loss of training and testing data that can be sorted when the model is taught from an enormous dataset. For MAE, the average MAE is 1.826 and 2.288 for training and testing. Losses are not so much in training as they are in testing data [27].

(5) Figures 4 and 5 show a graphical representation of experiment value (actual) and projected strength due to compression of fly-ash, calcined-clay-based geopolymer concrete at various temperatures, using RFR supervised learning algorithms for the training and testing phases. These data show that RFR models performed as per training and testing in forecasting geopolymer concrete compressive strength at various temperatures in terms of statistical performance.

(6) Supervised learning models, such as other artificial intelligence systems, have a limited range of scope and are heavily case-dependent. As a result, their generalizability is constrained, and therefore can only be used with a limited collection of trained data. Moreover, in contrast to other models, the created RFR model is capable of correctly and effectively predicting the compressive strength at varying temperatures. However, as the latest data arrive, this model can be adjusted to perform better.

Table 6. The training phase (compressive strength) with available RFR models' yielded statistical data from the applied prediction models.

\begin{tabular}{ccccc}
\hline \multirow{2}{*}{ Model } & MSE & \multicolumn{2}{c}{ Results of Training Performance } \\
& RMSE & $\mathbf{R}^{\mathbf{2}}$ & MAE \\
\hline RFR & 6.83 & 2.61 & 0.93 & 1.85 \\
\hline
\end{tabular}

Table 7. The testing phase (compressive strength) with available RFR models' yielded statistical data from the applied prediction models.

\begin{tabular}{ccccc}
\hline \multirow{2}{*}{ Model } & MSE & \multicolumn{2}{c}{ Results of Testing Performance } \\
& RMSE & $\mathbf{R}^{2}$ & MAE \\
\hline RFR & 10.41 & 3.23 & 0.58 & 3.07 \\
\hline
\end{tabular}




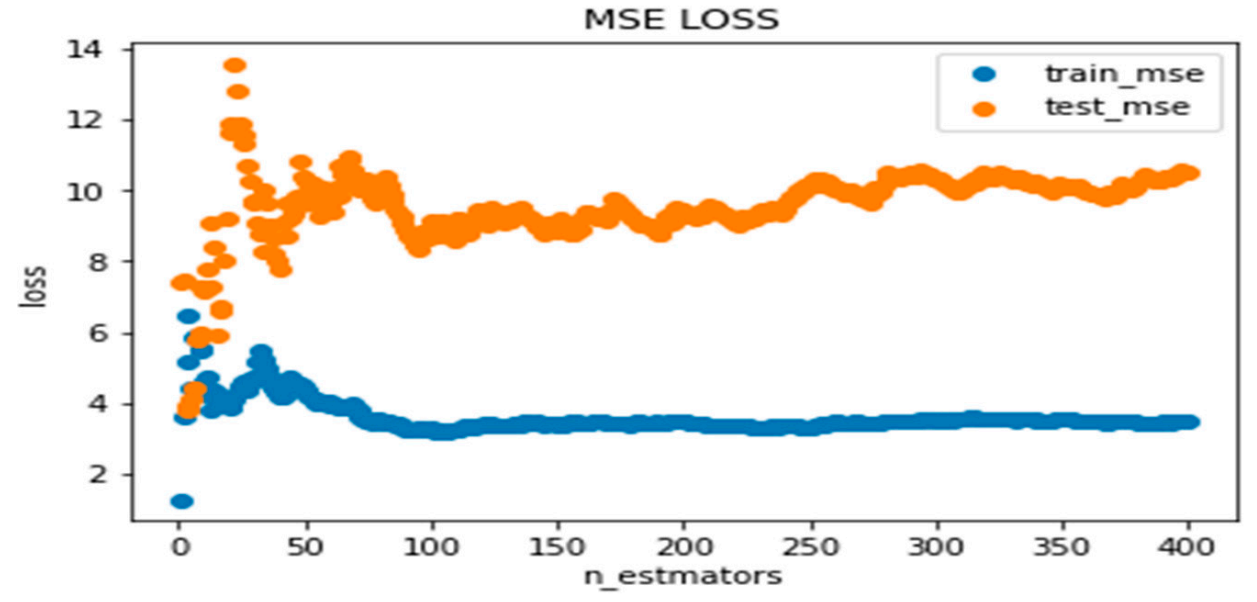

(a)

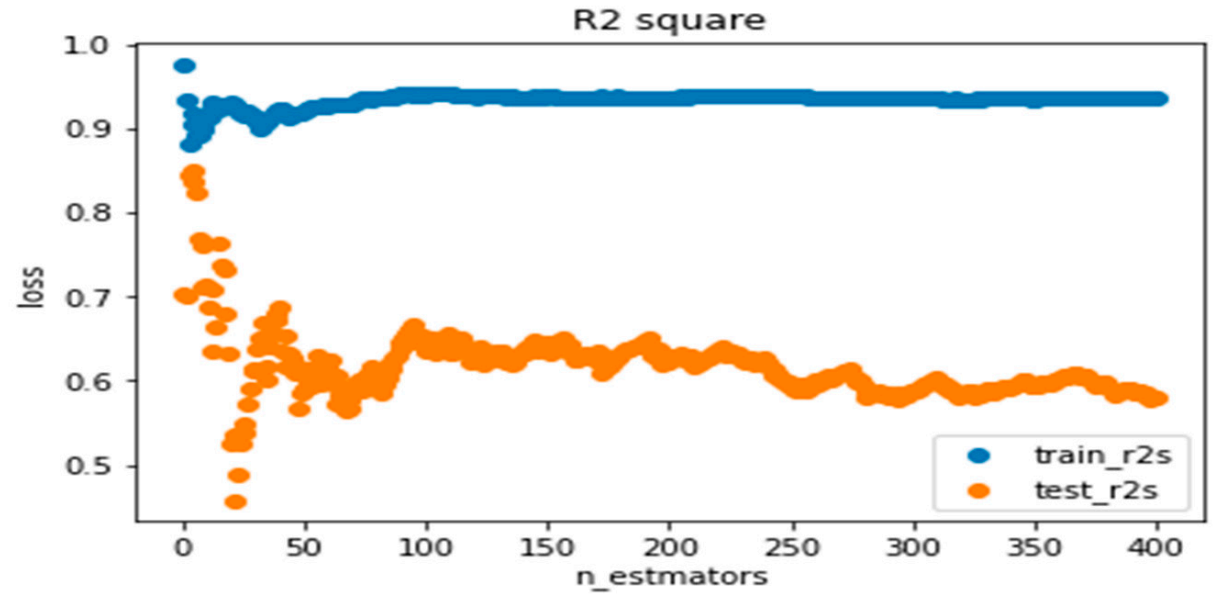

(b)

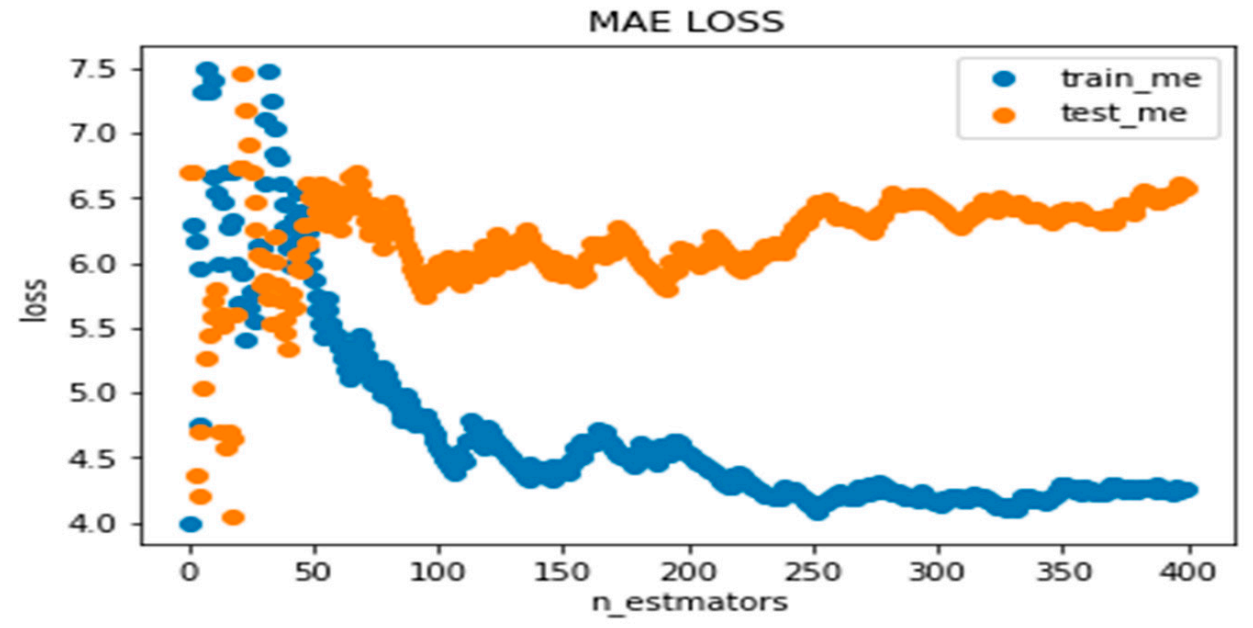

(c)

Figure 3. Losses in RFR. (a) MSE Losses in RFR (b) R2 Losses in RFR (c) MAE losses in RFR. 


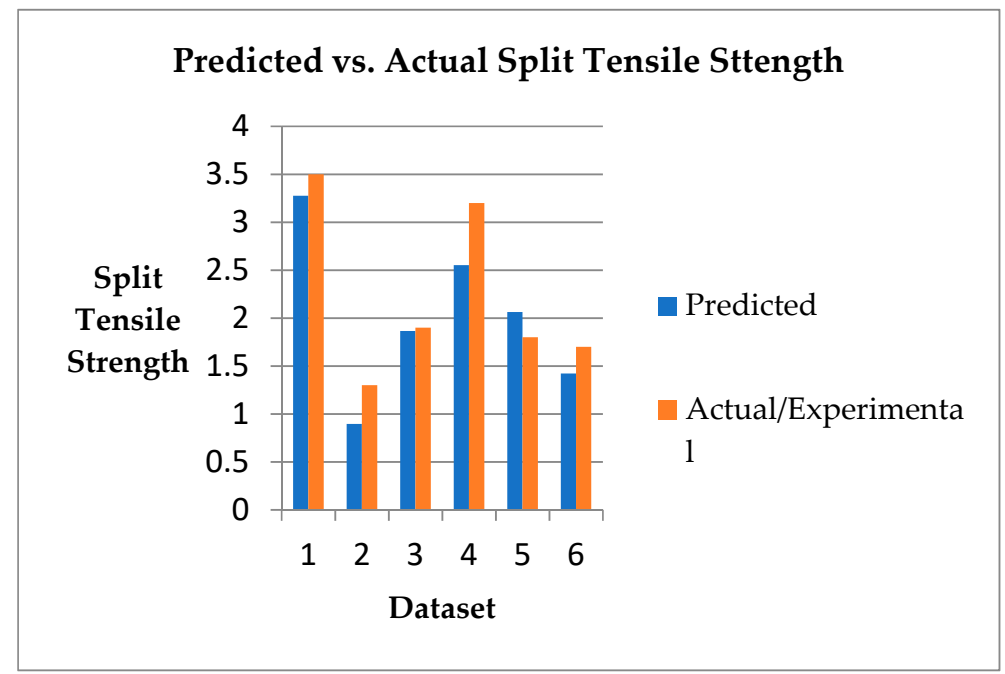

Figure 4. Graphical representation of experimental value (actual) and projected strength due to compression of fly-ash, calcined -clay-based geopolymer concrete.

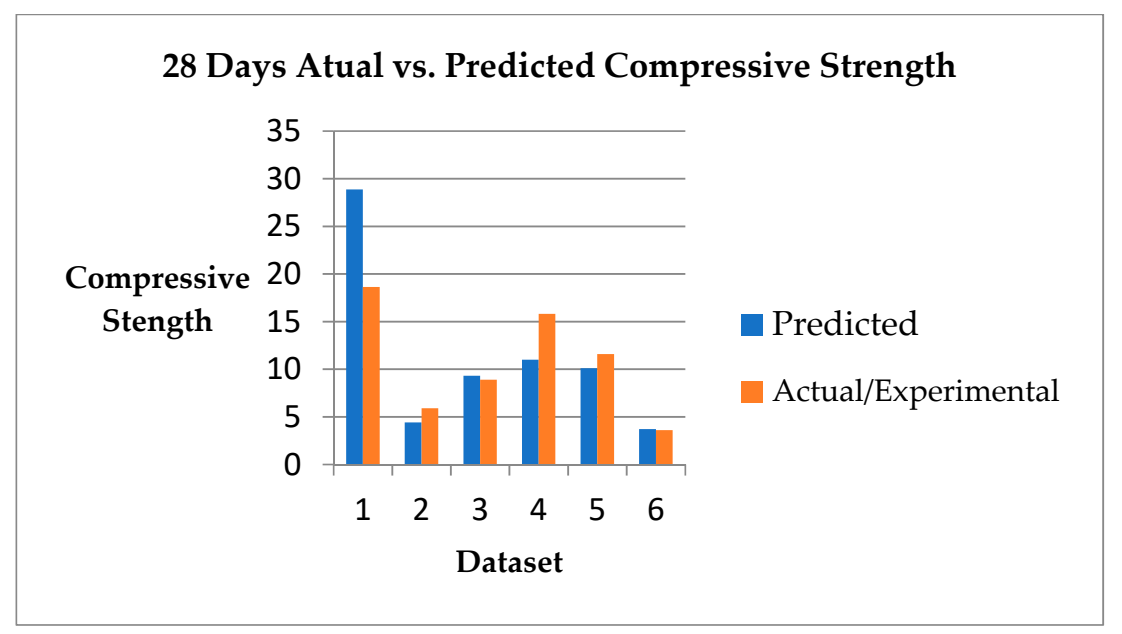

Figure 5. Graphical representation of experimental value (actual) and projected split tensile strength of fly-ash, calcined-clay-based geopolymer concrete.

Table 8. The training phase (split tensile strength) with available RFR models' yielded statistical data from the applied prediction models.

\begin{tabular}{ccccc}
\hline \multirow{2}{*}{ Model } & MSE & \multicolumn{2}{c}{ Results of Training Performance } \\
& RMSE & $\mathbf{R}^{2}$ & MAE \\
\hline RFR & 0.065 & 0.256 & 0.88 & 0.213 \\
\hline
\end{tabular}

Table 9. The testing phase (split tensile strength) with available RFR models' yielded statistical data from the applied prediction models.

\begin{tabular}{ccccc}
\hline Model & MSE & \multicolumn{2}{c}{ Results of Testing Performance } \\
& RMSE & $\mathbf{R}^{\mathbf{2}}$ & MAE \\
\hline RFR & 0.28 & 0.53 & 0.57 & 0.36 \\
\hline
\end{tabular}

\section{Conclusions}

1. In this work, RFR was used to predict the compressive strength at ambient temperature, $80^{\circ} \mathrm{C}$, and $100{ }^{\circ} \mathrm{C}$ curing temperature for 24 and $48 \mathrm{~h}$. The best result was 
shown by FACC geopolymer concrete for $5 \%$ calcined clay and $12 \mathrm{M} \mathrm{NaOH}$ solution at $100^{\circ} \mathrm{C}$ for $48 \mathrm{~h}$ curing.

2. The RFR model's predictive skills were evaluated by using statistical measure criteria, such as $R^{2}, M A E$, and RMSE. The $R^{2}$ value comes out to be 0.58 for the testing phase of RFR, which is an acceptable value of the coefficient of correlation. The training results of $R^{2}$ as 0.935 are also good for 28 days of compressive strength.

3. The findings of the testing phase demonstrated that the supervised learning models developed in this work were successful in predicting geopolymer concrete compressive strength at various ranges of temperature. This paper predicted 28 days of compressive and tensile strength.

4. Statistics research reveals that the RFR model is effective. Correctness is improved by reducing the erroneous gap between the actual and forecasted parameters. Various metrics, such as MAE, RMSE, $\mathrm{R}^{2}$, and MSE, were the deciding parameters.

5. As a result, the use of RFR in the domain of forecasting compressive strength at various temperatures as an alternative to destructive testing methods is reasonable and can be considered as a viable option, and the same is applied to tensile strength.

6. Due to the addition of weak classifiers (decision tree), random forest is an ensemble strategy that delivers a consistent performance between observed and forecasted values and gives the coefficient of determination $R^{2}$ as 0.58 .

Author Contributions: Conceptualization, P.G. and N.G.; methodology, P.G.; software, P.G.; validation, P.G., N.G. and K.K.S.; formal analysis, S.G.; investigation, K.K.S.; resources, P.G.; data curation, P.G.; writing—original draft preparation, P.G.; writing—review and editing, P.G.; visualization, S.G.; supervision, P.G.; project administration, N.G. All authors have read and agreed to the published version of the manuscript.

Funding: This research received no external funding.

Institutional Review Board Statement: Not applicable.

Informed Consent Statement: Not applicable.

Data Availability Statement: The data presented in this study are available on request from the corresponding author.

Conflicts of Interest: The authors declare no conflict of interest. No funding was provided from external sources.

\begin{tabular}{|c|c|}
\hline \multicolumn{2}{|c|}{ Abbreviation } \\
\hline Designation & Full Form \\
\hline FACC & fly ash calcined clay \\
\hline RFR & random forest regressor \\
\hline $\mathrm{NaOH}$ & sodium hydroxide \\
\hline $\mathrm{Na}_{2} \mathrm{SiO}_{3}$ & sodium silicate \\
\hline GEP & genetic-algorithm-based \\
\hline RMSE & root mean square error \\
\hline MAE & mean absolute error \\
\hline $\mathrm{R}^{2}$ & coefficient of correlation \\
\hline MSE & mean squared error \\
\hline GGBFs & ground granulated blast furnace slag \\
\hline
\end{tabular}

\section{References}

1. Aprianti, S.E. A Huge Number of Artificial Waste Material Can Be Supplementary Cementitious Material (SCM) for Concrete Production-A Review Part II. J. Clean. Prod. 2017, 142, 121515. [CrossRef]

2. Akbar, A.; Farooq, F.; Shafique, M.; Aslam, F.; Alyousef, R.; Alabduljabbar, H. Sugarcane bagasse ash-based engineered geopolymer mortar incorporating propylene fibers. J. Build. Eng. 2021, 33, 101492. [CrossRef]

3. Meesala, C.R.; Verma, N.K.; Kumar, S. Critical review on fly-ash based geopolymer concrete. Struct. Concr. 2020, $21,1013-1028$. [CrossRef] 
4. Nordin, N.; Abdullah, M.M.A.B.; Tahir, M.F.M.; Sandu, A.V.; Hussin, K. Utilization of Fly Ash Waste As Construction Material. Int. J. Conserv. Sci. 2016, 7, 161-166.

5. Benny, J. Behavior of Geopolymer Concrete Exposed to Elevated Temperatures. Ph.D. Thesis, School of Engineering Cochin University of Science and Technology, Kochi, India, 2015; pp. 1-181.

6. Chu, H.-H.; Khan, M.A.; Javed, M.; Zafar, A.; Ijaz Khan, M.; Alabduljabbar, H.; Qayyum, S. Sustainable use of fly-ash: Use of gene-expression programming (GEP) and multi-expression programming (MEP) for forecasting the compressive strength geopolymer concrete. Ain Shams Eng. J. 2021, in press. [CrossRef]

7. Duxson, P.; Provis, J.L. Designing Precursors for Geopolymer Cements. J. Am. Ceram. Soc. 2008, 91, 3864-3869. [CrossRef]

8. Farooq, F.; Amin, M.N.; Khan, K.; Sadiq, M.R.; Javed, M.F.; Aslam, F.; Alyousef, R. A comparative study of random forest and genetic engineering programming for the prediction of compressive strength of high strength concrete (HSC). Appl. Sci. 2020, 10, 7330. [CrossRef]

9. Abubakar, A.; Tabra, M. Predictive Capabilities of Multilayer Perceptron (MLP) in WEKA Algorithm for High Strength Concrete with Steel Fiber Addition. Cem. Based Compos. 2020, 2, 13-18. [CrossRef]

10. Shaqadan, A. Prediction of concrete mix strength using random forest model. Int. J. Appl. Eng. Res. 2016, 11, 11024-11029.

11. Pengcheng, L.; Xianguo, W.; Hongyu, C.; Tiemei, Z. Prediction of compressive strength of High-Performance Concrete by Random Forest algorithm. IOP Conf. Ser. Earth Environ. Sci. 2020, 552, 12020. [CrossRef]

12. Mai, H.V.T.; Nguyen, T.A.; Ly, H.B.; Tran, V.Q. Prediction Compressive Strength of Concrete Containing GGBFS using Random Forest Model. Adv. Civ. Eng. 2021, 2021, 6671448. [CrossRef]

13. Sun, Y.; Li, G.; Zhang, J.; Qian, D. Prediction of the Strength of Rubberized Concrete by an Evolved Random Forest Model. Adv. Civ. Eng. 2019, 2019, 5198583. [CrossRef]

14. Fernández-Jiménez, A.; Palomo, A. Characterisation of fly ashes. Potential reactivity as alkaline cements. Fuel 2003, 82, 2259-2265. [CrossRef]

15. Ogundiran, M.B.; Kumar, S. Synthesis of fly ash-calcined clay geopolymers: Reactivity, mechanical strength, structural and microstructural characteristics. Constr. Build. Mater. 2016, 125, 450-457. [CrossRef]

16. Ho, T.K. Random decision forests. In Proceedings of the 3rd International Conference on Document Analysis and Recognition, Montreal, QC, Canada, 14-16 August 1995; Volume 1, pp. 278-282. [CrossRef]

17. Breiman, L. Random forests. Mach. Learn. 2001, 45, 5-32. [CrossRef]

18. Farnaaz, N.; Jabbar, M.A. Random Forest Modeling for Network Intrusion Detection System. Procedia Comput. Sci. 2016, 89, 213-217. [CrossRef]

19. Rodriguez-Galiano, V.; Castillo, M.S.; Chica-Olmo, M.; Rivas, M.C. Machine learning predictive models for mineral prospectivity: An evaluation of Neural Networks, Random Forest, Regression Trees and Support Vector machines. Ore Geol. Rev. 2015, 71, 804-818. [CrossRef]

20. Kulkarni, V.Y.; Sinha, P.K. Pruning of Random Forest classifiers: A survey and future directions. In Proceedings of the 2012 International Conference on Data Science \& Engineering (ICDSE), Cochin, India, 18-20 July 2012; pp. 64-68. [CrossRef]

21. Farooq, F.; Ahmed, W.; Akbar, A.; Aslam, F.; Alyousef, R. Predictive modeling for sustainable high-performance concrete from industrial wastes: A comparison and optimization of models using ensemble learners. J. Clean. Prod. 2021, 292, 126032. [CrossRef]

22. Singh, B.; Sihag, P.; Tomar, A. Estimation of compressive strength of high-strength concrete by random forest and M5P model tree approaches. J. Mater. Eng. Struct. 2019, 6, 583-592.

23. Marani, A.; Nehdi, M.L. Machine learning prediction of compressive strength for phase change materials integrated cementitious composites. Constr. Build. Mater. 2020, 265, 120286. [CrossRef]

24. Ali Khan, M.; Zafar, A.; Akbar, A.; Javed, M.F.; Mosavi, A. Application of Gene Expression Programming (GEP) for the Prediction of Compressive Strength of Geopolymer Concrete. Materials 2021, 14, 1106. [CrossRef] [PubMed]

25. Moore, D.S.; Notz, W.; Fligner, M.A. The Basic Practice of Statistics; W.H. Freeman and Company: New York, NY, USA, 2013. Available online: https: / /books.google.co.in/books?id=aw61ygAACAAJ (accessed on 27 September 2021).

26. Han, Q.; Gui, C.; Xu, J.; Lacidogna, G. A generalized method to predict the compressive strength of high-performance concrete by improved random forest algorithm. Constr. Build. Mater. 2019, 226, 734-742. [CrossRef]

27. Young, B.A.; Hall, A.; Pilon, L.; Gupta, P.; Sant, G. Can the compressive strength of concrete be estimated from knowledge of the mixture proportions?: New insights from statistical analysis and machine learning methods. Cem. Concr. Res. 2019, 115, 379-388. [CrossRef] 